\title{
Seletividade fisiológica de inseticidas a Vespidae predadores de Ascia monuste orseis ${ }^{(1)}$
}

\author{
André Luiz Barreto Crespo(2), Marcelo Coutinho Picanço(2), Leandro Bacci(2), \\ Eliseu José Guedes Pereira(2) e Alfredo Henrique Rocha Gonring ${ }^{(2)}$
}

\begin{abstract}
Resumo - Este trabalho objetivou estudar a seletividade dos inseticidas carbaril, deltametrina, paratiom metílico, permetrina e triclorfom em relação a Ascia monuste orseis (Godart) (Lepidoptera: Pieridae) e a seus predadores Brachygastra lecheguana Latreille e Protonectarina sylveirae (Saussure) (Hymenoptera: Vespidae). Por meio de curvas de concentração-mortalidade e das concentrações letais para $90 \%$ da população $\left(\mathrm{CL}_{90}\right)$, calcularam-se os índices de seletividade diferencial $\left(\mathrm{ISD}_{90}\right)$, de toxicidade relativa, e de tolerância relativa $\left(\mathrm{ITRe}_{90}\right)$. O paratiom metílico e triclorfom apresentaram seletividade em favor de $B$. lecheguana $\left(\mathrm{ISD}_{90}=2,83\right.$ e 1,75) e $P$. sylveirae $\left(\mathrm{ISD}_{90}=2,95\right.$ e 3,59) em relação a $A$. monuste orseis. Deltametrina e permetrina apresentaram seletividade em favor de $P$. sylveirae (ISD $_{90}=1,98 \mathrm{e}$ 2,70 ) em relação a $A$. monuste orseis, mas não apresentaram seletividade em favor de $B$. lecheguana $\left(\mathrm{ISD}_{90}=0,21\right.$ e 0,64$)$. B. lecheguana foi menos tolerante a deltametrina, permetrina e triclorfom do que P. sylveirae ( $\operatorname{ITRe}_{90}=9,36,4,23$ e 2,05), e mais tolerante ao carbaril $\left(\mathrm{ITRe}_{90}=0,14\right)$. Os predadores apresentaram tolerância semelhante ao paratiom metílico $\left(\operatorname{ITRe}_{90}=1,04\right)$. As curvas de concentraçãomortalidade do carbaril, permetrina e triclorfom em ambos os predadores, de deltametrina em $B$. lecheguana, e de paratiom metílico em $P$. sylveirae, apresentaram maiores inclinações do que as curvas em A. monuste orseis.
\end{abstract}

Termos para indexação: Brachygastra lecheguana, Protonectarina sylveirae, controle de insetos, controle biológico.

\section{Insecticide physiological selectivity to Vespidae predators of Ascia monuste orseis}

\begin{abstract}
This work aimed to study the selectivity of the insecticides carbaryl, deltamethrin, methyl parathion, permethrin and trichlorfon in relation to Ascia monuste orseis (Godart) (Lepidoptera: Pieridae) and to their predators Brachygastra lecheguana Latreille and Protonectarina sylveirae (Saussure) (Hymenoptera: Vespidae). Based on concentration-response curves and lethal concentrations for $90 \%$ of the population $\left(\mathrm{LC}_{90}\right)$, the differential selectivity index $\left(\mathrm{DSI}_{90}\right)$, relative toxicity index and relative tolerance index $\left(\operatorname{ReTI}_{90}\right)$ were calculated. Methyl parathion and trichlorfon were selective to B. lecheguana $\left(\mathrm{DSI}_{90}=2.83\right.$ and 1.75) and P. sylveirae $\left(\mathrm{DSI}_{90}=2.95\right.$ and 3.59) against $A$. monuste orseis. Deltamethrin and permethrin were selective to P. sylveirae $\left(\mathrm{DSI}_{90}=1.98\right.$ and 2.70$)$ against A. monuste orseis, but weren't selective to B. lecheguana $\left(\mathrm{DSI}_{90}=0.21\right.$ and 0.64$)$. B. lecheguana was less tolerant to deltamethrin, permethrin and trichlorfon than P. sylveirae $\left(\operatorname{ReTI}_{90}=9.36,4.23\right.$ and $2.05)$, but the opposite was observed to carbaryl $\left(\operatorname{ReTI}_{90}=0.14\right)$. These two predators showed similar tolerance to methyl parathion $\left(\mathrm{ReTI}_{90}=1.04\right)$. Concentration-response curves of carbaryl, permethrin and trichlorfon to both predators, deltamethrin to B. lecheguana, and methyl parathion to P. sylveirae, showed greater slopes than these curves to A. monuste orseis.
\end{abstract}

Index terms: Brachygastra lecheguana, Protonectarina sylveirae, insect control, biological control.

(1) Aceito para publicação em 24 de maio de 2001.

(2) Universidade Federal de Viçosa, Dep. de Biologia Animal, CEP 36571-000 Viçosa, MG. Bolsista do CNPq. E-mail: picanco@mail.ufv.br

\section{Introdução}

As brássicas (crucíferas) constituem a família mais numerosa em termos de espécies oleráceas, totali- 
zando quatorze hortaliças, entre as quais o repolho (Brassica oleraceae var. capitata), a couve-flor (B. oleraceae var. botrytis), a couve-comum (B. oleraceae var. acephala), o brócolo (B. oleraceae var. italica) e a mostarda (B. juncea) destacam-se pela sua importância econômica (Filgueira, 2000). O curuquerê-da-couve, Ascia monuste orseis (Godart) (Lepidoptera: Pieridae), constitui uma das pragas-chave dessas culturas, provocando perdas causadas pela desfolha (Picanço \& Marquini, 1999; Picanço et al., 2000). O controle de A. monuste orseis é executado principalmente pela aplicação de inseticidas (Picanço \& Marquini, 1999; Picanço et al., 2000) como carbaril, deltametrina, paratiom metílico, permetrina e triclorfom, registrados para uso em seu controle em brássicas (Andrei, 1999).

Os agentes de controle biológico dessa praga são os pássaros (Pough \& Brower, 1977), parasitóides (Penteado-Dias, 1986), percevejos predadores (Picanço et al., 1997), e as vespas predadoras de lagartas (Picanço et al., 1998). Entre as vespas presentes em campos de couve, Bueno \& Souza (1993) relatam Brachygastra lecheguana Latreille e Protonectarina sylveirae (Saussure) (Hymenoptera: Vespidae). As populações destes inimigos naturais podem ser prejudicadas pelo uso de inseticidas nãoseletivos, e portanto, para a preservação das espécies benéficas ao agroecossistema é de extrema importância o uso de inseticidas seletivos. A seletividade pode ser classificada em seletividade ecológica e fisiológica. A seletividade fisiológica consiste no uso de inseticidas que sejam mais tóxicos à praga do que a seus inimigos naturais. Já a seletividade ecológica relaciona-se a formas de utilização dos inseticidas de modo a minimizar a exposição do inimigo natural ao inseticida (Pedigo, 1999).

Apesar da importância da seletividade na preservação do controle biológico natural de pragas em brássicas, pouco se conhece a respeito (Picanço et al., 1997, 1998).

O objetivo desta pesquisa foi estudar a seletividade fisiológica dos inseticidas carbaril, deltametrina, paratiom metílico, permetrina e triclorfom em relação a $A$. monuste orseis e a seus predadores $B$. lecheguana e $P$. sylveirae.

Pesq. agropec. bras., Brasília, v. 37, n. 3, p. 237-242, mar. 2002

\section{Material e Métodos}

Este trabalho foi realizado no Laboratório de Manejo Integrado de Pragas da Universidade Federal de Viçosa (UFV), Viçosa, MG, nos anos de 1995 a 1998. Os inseticidas utilizados foram carbaril $850 \mathrm{PM}$, deltametrina $25 \mathrm{CE}$, paratiom metílico $600 \mathrm{CE}$, permetrina $500 \mathrm{CE}$ e triclorfom $500 \mathrm{CE}$. Utilizaram-se lagartas de $4^{\circ}$ e $5^{\circ}$ ínstares de $A$. monuste orseis e adultos dos predadores $B$. lecheguana e $P$. sylveirae coletados em ninhos no Campus da UFV.

$\mathrm{O}$ delineamento experimental foi inteiramente casualizado, com quatro repetições. $\mathrm{Na}$ instalação do experimento, folhas de couve foram imersas em caldas inseticidas e em água (testemunha) por cinco segundos. Em todos os tratamentos empregou-se espalhante adesivo $\mathrm{N}$-Dodecil benzeno sulfonato de sódio $320 \mathrm{CE}$ na dosagem de $0,096 \mathrm{mg}$ de ingrediente ativo/mL de calda (Andrei, 1999). As folhas, mantidas por duas horas para retirar o excesso de umidade, foram acondicionadas em placas de Petri de $9 \mathrm{~cm}$ de diâmetro por $2 \mathrm{~cm}$ de altura. Em cada placa de Petri foram liberadas 10 lagartas ou Vespidae conforme o tratamento. As placas de Petri foram levadas para incubadora tipo BOD a $25 \pm 0,5^{\circ} \mathrm{C}$ e umidade relativa de $75 \pm 5 \%$. Vinte e quatro horas depois se realizaram as avaliações da mortalidade das lagartas de A. monuste orseis e dos Vespidae, e os resultados foram corrigidos em relação à mortalidade ocorrida na testemunha (Abbott, 1925). Por análise de próbite, determinaram-se curvas de concentração-mortalidade dos inseticidas em relação à lagarta A. monuste orseis e às duas espécies de vespas predadoras. Foram aceitas curvas cuja probabilidade de aceitação da hipótese de nulidade (de que os dados possuem distribuição de próbite) pelo teste $\chi^{2}$ fosse maior que 0,05 (Young $\&$ Young, 1998). Por meio destas curvas, foram estimadas as concentrações letais para $90 \%$ das populações $\left(\mathrm{CL}_{90}\right)$.

Foram calculados os índices de seletividade diferencial $\left(\mathrm{ISD}_{90}=\mathrm{CL}_{90}\right.$ do inseticida ao predador/CL $\mathrm{C}_{90}$ do inseticida à praga $)$, de toxicidade relativa $\left(\mathrm{ITR}_{90}=\right.$ maior $\mathrm{CL}_{90}$ do inseticida à espécie/CL $\mathrm{C}_{90}$ do inseticida à espécie) e de tolerância relativa de $P$. sylveirae em relação a $B$. lecheguana $\left(\right.$ ITRe $_{90}=\mathrm{CL}_{90}$ do inseticida a $P$. sylveirae $/ \mathrm{CL}_{90}$ do inseticida a $B$. lecheguana). Utilizando-se as curvas de concentração-mortalidade dos inseticidas em relação aos predadores e lagartas, foram estimadas mortalidades causadas aos Vespidae pelas concentrações dos inseticidas que causaram $90 \%$ de mortalidade a $A$. monuste orseis.

\section{Resultados e Discussão}

Os organofosforados paratiom metílico e triclorfom foram seletivos em favor de B. lecheguana, sendo 
2,8 e 1,7 vezes mais tóxicos às lagartas do que a este predador; as mortalidades estimadas deste Vespidae pelas $\mathrm{CL}_{90}$ destes inseticidas a A. monuste orseis foram de $33,2 \%$ e $57,0 \%$, respectivamente. O carbamato carbaril apresentou toxicidade semelhante ao predador B. lecheguana e à sua presa $A$. monuste orseis $\left(\mathrm{ISD}_{90}=1,02\right)$, e a mortalidade estimada deste Vespidae pela $\mathrm{CL}_{90}$ deste inseticida a $A$. monuste orseis foi $89,44 \%$. Os piretróides permetrina e deltametrina não apresentaram seletividade em favor do predador $B$. lecheguana, e foram cerca de 1,6 e 5,0 vezes mais tóxicos ao predador do que às lagartas de A. monuste orseis (ISD I0 $=0,64$ e 0,21, respectivamente); a mortalidade estimada deste Vespidae pelas $\mathrm{CL}_{90}$ destes inseticidas a A. monuste orseis foi de $100 \%$ (Tabelas 1 e 2).

Os organofosforados paratiom metílico e triclorfom e os piretróides deltametrina e permetrina foram seletivos em favor do predador $P$. sylveirae, e 2,95, 3,59, 1,98 e 2,70 vezes mais tóxicos às lagartas de A. monuste orseis do que ao predador, respectivamente. A mortalidade estimada deste Vespidae pela $\mathrm{CL}_{90}$ destes inseticidas a A. monuste orseis foi de $0,00,28,00,71,30$ e $54,30 \%$, respectivamente. O carbamato carbaril não apresentou seletividade em favor do predador $P$. sylveirae, e foi 7,07 vezes mais tóxico ao predador do que às lagartas de $A$. monuste orseis $\left(\mathrm{ISD}_{90}=0,14\right)$; a mortalidade deste Vespidae pela $\mathrm{CL}_{90}$ deste inseticida a $A$. monuste orseis foi de $100 \%$ (Tabelas 1 e 2 ).

Há relatos, na literatura, apontando para a seletividade dos inseticidas piretróides deltametrina e permetrina em favor de Vespidae (Leite et al., 1998;
Picanço et al., 1998; Moura et al., 2000) e de Doru luteipes (Scudder) (Dermaptera: Forficulidae) (Faleiro et al., 1995), e do organofosforado triclorfom em favor de Vespidae predadores (Picanço et al., 1998). A menor sensibilidade da acetilcolinesterase dos predadores a inseticidas organofosforados do que a da espécie-praga (Voss, 1980) pode ser responsável pela seletividade apresentada pelo paratiom metílico e triclorfom em favor de $B$. lecheguana e $P$. sylveirae. O caráter lipofílico de alguns inseticidas, associado à espessura e composição lipídica da cutícula dos insetos, é responsável pela maior penetração do produto na cutícula e sua translocação até o alvo de ação (Leite et al., 1998). A lipofilicidade é inversamente proporcional à solubilidade do inseticida em água, sendo que compostos lipofílicos, dada a sua semelhança com a cutícula, geralmente penetram em maiores taxas no corpo do inseto. Assim, esse mecanismo pode também ser responsável pela seletividade do triclorfom, cuja solubilidade em água é elevada $(12 \%)$, mas não explica a seletividade apresentada pelo paratiom metílico, pois sua solubilidade em água é muito baixa (55 ppm) (Farm Chemicals Handbook, 2001).

A seletividade dos piretróides em favor de P. sylveirae obtida neste trabalho pode estar associada à maior taxa de metabolização do composto pelo inimigo natural do que pela praga, ou a alterações no alvo de ação dos inseticidas no inimigo natural (Yu, 1987). Este mesmo autor relata, ainda, que a metabolização dos piretróides por oxidases microssomais e esterases acarretam maior destoxificação destes inseticidas no percevejo-predador Podisus

Tabela 1. Índices de seletividade diferencial $\left(\mathrm{ISD}_{90}\right)$, mortalidade estimada dos Vespidae pelas concentrações letais para 90\% das populações $\left(\mathrm{CL}_{90}\right)$ dos inseticidas para Ascia monuste orseis (mortalidade), índices de toxicidade relativa $\left(\mathrm{ITR}_{90}\right)$ e índices de tolerância relativa (ITRe $\left.{ }_{90}\right)$ de cinco inseticidas usados no controle de $A$. monuste orseis em relação a adultos dos Vespidae predadores Brachygastra lecheguana e Protonectarina sylveirae. Viçosa, MG, 1995/1998(1).

\begin{tabular}{|c|c|c|c|c|c|c|c|c|}
\hline \multirow[t]{2}{*}{ Inseticida } & \multicolumn{4}{|c|}{ B. lecheguana } & \multicolumn{3}{|c|}{ P. sylveirae } & A. monuste orseis \\
\hline & $\mathrm{ISD}_{90}$ & Mortalidade & $\mathrm{ITR}_{90}$ & $\mathrm{ITRe}_{90}$ & $\mathrm{ISD}_{90}$ & Mortalidade & $\mathrm{ITR}_{90}$ & $\mathrm{ITR}_{90}$ \\
\hline Carbaril & 1,02 & $89,44 \%$ & 1,00 & 0,14 & 0,14 & $100,00 \%$ & 4,81 & 1,00 \\
\hline Deltametrina & 0,21 & $100,00 \%$ & 627,55 & 9,36 & 1,98 & $71,30 \%$ & 44,83 & 130,71 \\
\hline Paratiom metílico & 2,83 & $33,25 \%$ & 5,70 & 1,04 & 2,95 & $0,00 \%$ & 3,65 & 15,84 \\
\hline Permetrina & 0,64 & $100,00 \%$ & 59,00 & 4,23 & 2,70 & $54,30 \%$ & 9,33 & 37,14 \\
\hline Triclorfom & 1,75 & $57,00 \%$ & 3,07 & 2,05 & 3,59 & $28,00 \%$ & 1,00 & 5,28 \\
\hline
\end{tabular}

${ }^{(1)} \mathrm{ISD}_{90}: \mathrm{CL}_{90}$ do inseticida para o inimigo natural/CL $\mathrm{CL}_{90}$ do inseticida para lagartas de A. monuste orseis; $\mathrm{ITR}_{90}$ : maior $\mathrm{CL}_{90}$ para a espécie/CL 90 do inseticida para a espécie; ITRe ${ }_{90}: \mathrm{CL}_{90}$ do inseticida para P. sylveirae/CL $\mathrm{CL}_{90}$ do inseticida para B. lecheguana. 
maculiventris (Say) (Heteroptera: Pentatomidae) do que em suas presas. Modificações nos canais de sódio alterando a sensibilidade das enzimas (Na-K)ATPase e $\mathrm{Mg}_{2}$-ATPase podem também ser responsáveis pela seletividade desses inseticidas (Zhao et al., 1992; Leng \& Xiao, 1995). A ausência desses mecanismos em $B$. lecheguana pode ser a razão da menor tolerância apresentada por este predador aos piretróides. A elevada lipofilicidade de deltametrina e permetrina (menos que 0,002 ppm e $1 \mathrm{ppm}$ de solu- bilidade em água, respectivamente) (Farm Chemicals Handbook, 2001), associada à espessura e composição lipídica da cutícula, também pode ser responsável pela maior penetração desses piretróides neste predador.

Com base nos índices de toxicidade relativa (ITR) os inseticidas podem ser apresentados em ordem decrescente de potência em relação a lagartas de A. monuste orseis e ao predador B. lecheguana assim: deltametrina $>$ permetrina $>$ paratiom metílico $>$

Tabela 2. Equação de regressão, concentração letal para $90 \%$ da população $\left(\mathrm{CL}_{90}\right)$, qui-quadrado $\left(\chi^{2}\right)$ e probabilidade das curvas de concentração-mortalidade de cinco inseticidas em lagartas de Ascia monuste orseis e em adultos dos Vespidae predadores Brachygastra lecheguana e Protonectarina sylveirae. Viçosa, MG, 1995/1998.

\begin{tabular}{|c|c|c|c|c|}
\hline Inseticida & Equação $^{(1)}$ & $\mathrm{CL}_{90}(\mathrm{mg} \text { de i.a. } / \mathrm{mL})^{(2)}$ & $\chi^{2}$ & Probabilidade \\
\hline & \multicolumn{4}{|c|}{ Lagartas de $A$. monuste orseis } \\
\hline Carbaril & $y=6,82+3,22 x$ & $\begin{array}{c}0,6797 \\
(0,5836-0,8284)\end{array}$ & 2,353 & 0,309 \\
\hline Deltametrina & $y=19,96+6,00 x$ & $\begin{array}{c}0,0052 \\
(0,0047-0,0061)\end{array}$ & 1,405 & 0,500 \\
\hline Paratiom metílico & $y=13,02+4,93 x$ & $\begin{array}{c}0,0429 \\
(0,0382-0,0499)\end{array}$ & 3,715 & 0,293 \\
\hline Permetrina & $y=9,65+1,94 x$ & $\begin{array}{c}0,0183 \\
(0,0134-0,0286)\end{array}$ & 7,746 & 0,100 \\
\hline \multirow[t]{2}{*}{ Triclorfom } & $y=8,19+2,14 x$ & $\begin{array}{c}0,1287 \\
(0,1018-0,1766) \\
\end{array}$ & 0,258 & 0,879 \\
\hline & \multicolumn{4}{|c|}{ Adultos de $B$. lecheguana } \\
\hline Carbaril & $y=7,05+4,77 x$ & $\begin{array}{c}0,6903 \\
(0,5171-1,6090)\end{array}$ & 1,508 & 0,526 \\
\hline Deltametrina & $y=46,28+13,61 x$ & $\begin{array}{c}0,0011 \\
(0,0011-0,0012)\end{array}$ & 0,778 & 0,856 \\
\hline Paratiom metílico & $y=9,75+3,79 x$ & $\begin{array}{c}0,1212 \\
(0,1017-0,1574)\end{array}$ & 0,861 & 0,837 \\
\hline Permetrina & $y=36,23+15,51 x$ & $\begin{array}{c}0,0117 \\
(0,0112-0,0126)\end{array}$ & 3,514 & 0,170 \\
\hline \multirow[t]{2}{*}{ Triclorfom } & $y=9,21+4,53 x$ & $\begin{array}{c}0,2251 \\
(0,1932-0,2849)\end{array}$ & 1,902 & 0,612 \\
\hline & \multicolumn{4}{|c|}{ Adultos de P. sylveirae } \\
\hline Carbaril & $y=13,69+7,29 x$ & $\begin{array}{c}0,0961 \\
(0,0897-0,1051)\end{array}$ & 4,173 & 0,122 \\
\hline Deltametrina & $y=11,18+2,46 x$ & $\begin{array}{c}0,0103 \\
(0,0089-0,0128)\end{array}$ & 8,306 & 0,080 \\
\hline Paratiom metílico & $y=16,91+11,84 x$ & $\begin{array}{c}0,1266 \\
(0,1198-0,1363)\end{array}$ & 4,382 & 0,222 \\
\hline Permetrina & $y=9,80+2,70 x$ & $\begin{array}{c}0,0495 \\
(0,0410-0,0629)\end{array}$ & 9,992 & 0,075 \\
\hline Triclorfom & $y=7,41+3,36 x$ & $\begin{array}{c}0,4618 \\
(0,4080-0,5387)\end{array}$ & 11,040 & 0,050 \\
\hline
\end{tabular}

(1)y: Mortalidade em próbite; $\mathrm{x}$ : logaritmo da concentração $\left(\mathrm{mg}\right.$ de i.a./mL). ${ }^{(2)}$ Os números entre parênteses se referem ao intervalo de confiança das $\mathrm{CL}_{90}$ a $95 \%$ de probabilidade. 
triclorfom > carbaril. A ordem decrescente de potência dos inseticidas em relação ao predador P. sylveirae foi deltametrina $>$ permetrina $>$ carbaril $>$ paratiom metílico $>$ triclorfom (Tabela 1). As ordens decrescentes de potência mostram que os piretróides foram mais potentes que os demais inseticidas para as espécies estudadas, resultados esses que corroboram os obtidos por Batalha et al. (1995). Segundo Naumann (1990), a alta potência dos piretróides está associada a sua alta taxa de penetração no corpo de inseto por diversas rotas e também ao seu mecanismo de ação (interferem na abertura e conformação dos canais de $\mathrm{Na}^{+}$dos neurônios).

P. sylveirae foi cerca de nove vezes mais tolerante a deltametrina, quatro vezes mais tolerante a permetrina e duas vezes mais tolerante ao triclorfom do que B. lecheguana. Já $B$. lecheguana foi cerca de sete vezes mais tolerante ao carbaril do que $P$. sylveirae. Os predadores $B$. lecheguana $\mathrm{e}$ $P$. sylveirae apresentaram tolerâncias semelhantes ao paratiom metílico (Tabela 1). As razões das diferenças de tolerância das espécies de Vespidae aos inseticidas talvez sejam as mesmas da seletividade destes em favor dos predadores. Gonring et al. (1999), estudando a seletividade de inseticidas a Vespidae predadores em relação a Grapholita molesta (Busch) (Lepidoptera: Olethreutidae), verificaram que $P$. sylveirae foi menos tolerante a deltametrina do que Protopolybia exigua (Saussure) e Polistes versicolor versicolor Olivier (Hymenoptera: Vespidae). Gusmão et al. (2000), estudando a seletividade de inseticidas a $B$. lecheguana em relação a Leucoptera (=Perileucoptera) coffeella (Guérin-Meneville) (Lepidoptera: Lyonetiidae), verificaram que $B$. lecheguana foi menos tolerante a deltametrina que Apoica pallens Fabr. e $P$. versicolor versicolor (Hymenoptera: Vespidae). Esses resultados, assim como os obtidos no presente trabalho, sugerem que $B$. lecheguana, comparado a outros Vespidae predadores, é menos tolerante a piretróides.

As curvas de concentração-mortalidade do carbaril, permetrina e triclorfom em ambos predadores, deltametrina em $B$. lecheguana e paratiom metílico em $P$. sylveirae, apresentaram maiores inclinações que as curvas em $A$. monuste orseis. As curvas com inclinações menos elevadas foram de permetrina $\mathrm{e}$ triclorfom em P. sylveirae. As curvas com inclinações mais elevadas foram de deltametrina e permetrina em B. lecheguana e de paratiom metílico em $P$. sylveirae (Tabela 2). As maiores inclinações apresentadas pelas curvas de concentração-mortalidade dos inseticidas para os predadores do que para lagartas de A. monuste orseis indicam que pequenas variações nas doses desses inseticidas ocasionam maiores variações nas mortalidades dos predadores do que da praga (Moura et al., 2000). Assim, é de suma importância a calibração correta das doses desses inseticidas, para se evitar efeitos nocivos desses inseticidas sobre esses predadores.

\section{Conclusões}

1. Variações nas doses de carbaril, deltametrina, permetrina e triclorfom ocasionam maiores variações na mortalidade de B. lecheguana do que em A. monuste orseis.

2. Variações nas doses de carbaril, paratiom metílico, permetrina e triclorfom ocasionam maiores variações na mortalidade de $P$. sylveirae, do que em A. monuste orseis.

3. B. lecheguana é menos tolerante a deltametrina, permetrina e triclorfom do que $P$. sylveirae, e mais tolerante a carbaril; esses dois predadores apresentam tolerância semelhante ao paratiom metílico.

4. Paratiom metílico e triclorfom são seletivos em favor de B. lecheguana e P. sylveirae em relação a A. monuste orseis.

5. Deltametrina e permetrina são seletivos em favor de $P$. sylveirae em relação a $A$. monuste orseis, mas não são seletivos em favor de $B$. lecheguana.

\section{Referências}

ABBOTT, W. S. A method of computing the effectiveness of an insecticide. Journal of Economic Entomology, Lanham, v. 18 , n. 3, p. 265-267, 1925.

ANDREI, E. Compêndio de defensivos agrícolas. 6. ed. São Paulo: Andrei, 1999. 676 p.

BATALHA, V. C.; ZANUNCIO, J. C.; PICANÇO, M. C.; SEDIYAMA, C. S. Seletividade de inseticidas aos predadores Podisus nigrispinus (Dallas, 1851) e Supputius cincticeps (Stal, 1860) (Heteroptera: Pentatomidae) e a sua presa Lepidoptera. Revista Árvore, Viçosa, MG, v. 19, n. 3, p. 382-395, 1995. 
BUENO, V. H. P.; SOUZA, B. M. Ocorrência e diversidade de insetos predadores e parasitóides na cultura de couve Brassica oleracea var. acephala em Lavras, MG, Brasil. Anais da Sociedade Entomológica do Brasil, Porto Alegre, v. 22, n. 1, p. 5-18, 1993.

FALEIRO, F. G.; PICANÇO, M. C.; PAULA, S. V.; BATALHA, V. C. Seletividade de inseticidas a Spodoptera frugiperda (J.E. Smith) (Lepidoptera: Noctuidae) e ao predador Doru luteipes (Scudder) (Dermaptera: Forficulidae). Anais da Sociedade Entomológica do Brasil, Londrina, v. 24, n. 2, p. 247-252, 1995.

FARM chemicals handbook. Willoughby: Meister, 2001. $1000 \mathrm{p}$.

FILGUEIRA, F. A. R. Novo manual de olericultura: agrotecnologia moderna na produção e comercialização de hortaliças. Viçosa, MG: UFV, 2000. 402 p.

GONRING, A. H. R.; PICANÇO, M.; MOURA, M. F.; BACCI, L. Seletividade de inseticidas, utilizados no controle de Grapholita molesta (Busch) (Lepidoptera: Olethreutidae) em pêssego: a Vespidae predadores. Anais da Sociedade Entomológica do Brasil, Londrina, v. 28, n. 2, p. 301-306, 1999.

GUSMÃO, M. R.; PICANÇO, M.; GONRING, A. H. R.; MOURA, M. F. Seletividade físiológica de inseticidas a Vespidae predadores do bicho-mineiro-do-cafeeiro. Pesquisa Agropecuária Brasileira, Brasília, v. 35, n. 4 , p. 681-686, abr. 2000.

LEITE, G. L. D.; PICANÇO, M.; GUEDES, R. N. C.; GUSMÃO, M. R. Selectivity of insecticides with and without mineral oil to Brachygastra lecheguana (Hymenoptera: Vespidae): a predator of Tuta absoluta (Lepidoptera: Gelechiidae). Ceiba, Tegucigalpa, v. 39, n. 1, p. 3-6, 1998.

LENG, X. F.; XIAO, D. Q. Effect of deltamethrin on protein phosphorylation of housefly brain synaptosomes. Pesticide Science, Chichester, v. 44, n. 1, p. 88-89, 1995.

MOURA, M. F. de; PICANÇO, M.; GONRING, A. H. R.; BRUCKNER, C. H. Seletividade de inseticidas a três Vespidae predadores de Dione juno juno (Lepidoptera: Heliconidae). Pesquisa Agropecuária Brasileira, Brasília, v. 35, n. 2, p. 251-257, fev. 2000.

NAUMANN, K. Synthetic pyrethroid insecticides: structures and properties. Berlin: Springer, 1990. 241 p.

PEDIGO, L. P. Entomology and pest management. 3. ed. Upper Saddle River: Prentice Hall, 1999. 691 p.
PENTEADO-DIAS, A. M. Parasitismo de Ascia monuste orseis (Latreille, 1819) (Lepidoptera: Pieridae) por Cotesia glomerata (L., 1758) (Hymenoptera: Braconidae: Microgastrinae). Revista Brasileira de Entomologia, São Paulo, v. 30, n. 2, p. 257-259, 1986.

PICANÇO, M. C.; MARQUINI, F. Manejo integrado de pragas de hortaliças em ambiente protegido. Informe Agropecuário, Belo Horizonte, v. 20, n. 200/201, p. 126133, 1999.

PICANÇO, M. C.; GUSMÃO, M. R.; GALVAN, T. L. Manejo integrado de pragas de hortaliças. In: ZAMBOLIM, L. (Ed.). Manejo integrado de doenças, pragas e ervas daninhas. Viçosa, MG: UFV, 2000. v. 2, p. 275-324.

PICANÇO, M.; RIBEIRO, L. J.; LEITE, G. L. D.; GUSMÃO, M. R. Seletividade de inseticidas a Polybia ignobilis (Haliday) (Hymenoptera: Vespidae) predador de Ascia monuste orseis (Godart) (Lepidoptera: Pieridae). Anais da Sociedade Entomológica do Brasil, Londrina, v. 27, n. 1, p. 85-90, 1998.

PICANÇO, M.; RIBEIRO, L. J.; LEITE, G. L. D.; ZANUNCIO, J. C. Seletividade de inseticidas a Podisus nigrispinus predador de Ascia monuste orseis. Pesquisa Agropecuária Brasileira, Brasília, v. 32, n. 4, p. 369-372, abr. 1997.

POUGH, F. H.; BROWER, L. P. Predation by birds on great southern white butterflies as a function of palatability, sex, and habit. American Midland Naturalist, Notre Dame, v. 98, n. 1, p. 50-58, 1977.

VOSS, G. Cholinesterase auto analysis: a rapid method for biochemical studies on susceptible and resistant insects. Journal of Economic Entomology, Lanham, v. 73, n. 2, p. 189-192, 1980.

YOUNG, L. J.; YOUNG, J. H. Statistical ecology: a population perspective. Boston: Kluwer Academic, 1998. $565 \mathrm{p}$.

YU, S. J. Biochemical defense capacity in the spined soldier bug (Podisus maculiventris) and its lepidopterous prey. Pesticide Biochemical Physiology, San Diego, v. 28, n. 3, p. 216-223, 1987.

ZHAO, W. Q.; FENG, G. L.; SUN, Y. Q.; SHAO, Y. An important resistance mechanism of housefly to DDT and pyrethroids-CSN insensitivity. Acta Entomologica, Prague, v. 35, n. 4, p. 393-398, 1992. 